\title{
Orientasi kewirausahaan terhadap keberlanjutan usaha kerajinan pandai besi di Kecamatan Tellu Limpoe Kabupaten Sidrap
}

\author{
Herminawaty Abubakar ${ }^{1}$, Nurhidayanti S. ${ }^{2}$ \\ ${ }^{1}$ Fakultas Ekonomi, Universitas Bosowa \\ ${ }^{2}$ STIM Lasharan Jaya
}

\begin{abstract}
The existence of tra ditional blacksmith craftsmen in Tellu Limpoe Subdistrict, Sidra p Regency is now threatened with being displaced by machine technology. Constraints faced by blacksmith craftsmen are raw materials and equipment that are still tra ditional, ca pital production costs, raw materials that are difficult to ob tain, ha ve not been able to take advantage of advances in information and technology a nd market competition. The production technology used by blacksmiths is still conventional and is a hereditary skill, as well as the design has not been market oriented, so the quality of the products produced cannot compete especially with simila r p ro duc ts produced by industries that have used modern technology. This service aims to improve the welfare of bla ck smith craftsmen and the community in Tellu Limpoe District so that this handicraft business can survive amid competition in factory production. The method used in this service is in the form of socia lization, training, mentoring and guidance of blacksmith craftsmen. The results of devotion in the form of mindset changes, in crea sed managerial skills and increased income of blacksmith craftsmen.
\end{abstract}

Key words: increased income, entrepreneurial orientation, blacksmith's craft

\section{PENDAHULUAN}

Usaha mikro, kecil dan menengah (UMKM) merupakan kelompok usaha yang paling dapat bertahan ketika krisis ekonomi melanda negeri ini. Perkembangan jumlah unit usaha kecil menengah yang terus meningkat, tentunya akan dapat membuka lapangan kerja yang besar. Usaha mikro, kecil dan menengah (UMKM) merupakan bagian dari usaha nasional yang berperan penting dalam mewujudkan tujuan pembangunan nasional. UMKM juga dapat dianggap sebagai lokomotif pertumbuhan ekonomi nasional dan regional (daerah), karena berpotensi alam memberdayakan semua sumber daya yang ada dan mendorong tumbuhnya pengembangan kewirausahaan. Peranan UMKM di Indonesia yaitu: (1) peningkatan kesempatan kerja, (2) pemerataan pendapatan, (3) pembangunan ekonomi pedesaan, (4) peningkatan ekspor nonmigas dan (5) berkontribusi terhadap peningkatan PDB (Tambunan, 2009).

Pemerintah memberi perhatian yang sangat besar terhadap perkembangan Usaha Mikro Kecil Dan Menengah (UMKM). Tidak saja jumlah UMKM di Indonesia mendominasi, tetapi juga
UMKM dapat lebih bertahan dari terpaan krisis global. Berbagai inisiatif selalu diusahakan oleh pemerintah melalui pemerintah melalui Kementerian Negara Koperasi dan Usaha Kecil Menengah agar semakin banyak individu mau menekuni dunia wirausaha dalam bentuk pendirian UMKM. UMKM menyediakan kesempatan kerja yang sangat besar, sehingga UMKM di Indonesia memerlukan perhatian khusus agar dapat terus tumbuh dan mengembangkan usahanya. Namun demikian usaha kecil ini masih dipandang sebagai usaha yang lemah kinerjanya.

Terdapat banyak faktor yang mempengaruhi kinerja UMKM diantaranya faktor lingkungan bisnis eksternal seperti kebijakan pemerintah, kekuatan hukum dan politik, teknologi, sumber daya, pesaing, selera pelanggan, dan pengelolaan perusahaan. Faktor yang menghambat keberhasilan suatu usaha dipengaruhi oleh: a) usaha dikelola oleh manajer yang kurang mampu dan kurang berpengalaman dalam menjalankan tugas, b) lemahnya sistem kontrol/pengawasan (Ardiansyah, 2017).

Industri kecil juga tak terlepas dari pemanfaatan sumber daya yang ada baik itu sumber daya 
manusia maupun sumber daya alam. Setiap manusia mempunyai daya adaptasi untuk mempertahankan kelangsungan hidupnya dengan menggunakan kemampuan dan pengetahuan yang dimiliki. Manusia dapat menjadikan sumber daya alam sebagai kekayaan yang dapat mendukung kehidupannya.

Kabupaten Sidrap terdapat sentra pandai besi (mallanro atau panre bessi), tepatnya di Kecamatan Tellu Limpoe. Produksinya tidak hanya dipasarkan di Sulawesi, tetapi juga Kalimantan, Papua, dan daerah lainnya di Indonesia. Hampir seluruh warga desa setempat menekuni profesi sebagai pandai besi. Para pengrajin besi ini bisa memproduksi rata-rata 289.950 buah per bulan. Seperti parang, pisau, sabit, cangkul, dan alat-alat pertanian.

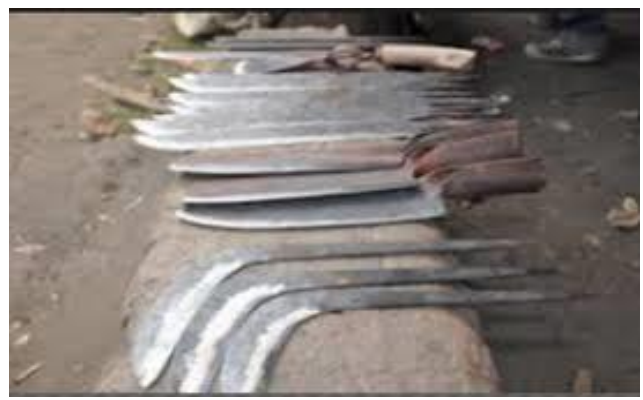

Gambar1. Hasil kerajinan pandai besi

Usaha ini telah dilakukan secara turun temurun dan merupakan usaha keluarga, di Kecamatan Tellu Limpoe masyarakat yang bergantung pada sektor ini memperoleh penghasilan minim karena masih melakukan proses produksi secara manual, sementara penghasilan yang mereka dapatkan tidak seimbang lagi dengan biaya produksi. Kebanyakan dari mereka adalah laki-laki dan berasal dari masyarakat di kelurahan tersebut. Peralatan yang dipakai masih tergolong sederhana. Tungku terbuat dari batu yang berfungsi sebagai tempat memanaskan besi serta pemompa angin yang dilakukan secara manual dan peralatan tersebut terbuat dari bambu yang berfungsi menghembuskan angin ke tungku dengan cara memompa.

Keberadaan pengrajin pandai besi tradisional kini terancam tergusur teknologi mesin. Di tempat lain, pemilik usaha alat besi banyak yang telah memodernisasi alat produksinya. Mesin meng- gantikan peran tukang pukul yang selama ini menjadi identitas pandai besi tradisional. Mesin akan bekerja menempa besi panas hingga gepeng sesuai dengan keinginan. Alat modern itu tentu memudahkan sekaligus menguntungkan pemilik usaha. Biaya produksi bisa ditekan, karena jumlah tenaga kerja dapat dikurangi. Hal ini sangat bertolak belakang dari kondisi yang dihadapi pengrajin pandai besi di Kelurahan Massepe Kecamatan Tellue Limpoe, dimana pengrajin pandai besi diperhadapkan pada beberapa masalah yang rumit.

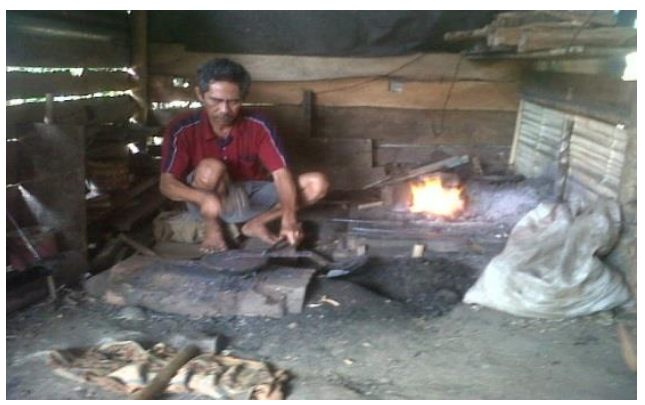

Gambar 2. Proses produksi

Kendala utama yang dihadapi pengrajin pandai besi ini adalah bahan baku serta peralatan yang masih tradisional, permodalan biaya produksi, bahan mentah yang sulit diperoleh. Belum lagi para pandai besi dihadapkan dengan persaingan pasar dimana mereka bersaing dengan hasil produksi pabrikan yang di jual di toko-toko. Hasil produksi pabrikan tersebut lebih variatif bentuk dan modelnya. Selain itu, kendala yang dihadapi pengrajin pandai besi adalah lemahnya tingkat SDM para perajin dan lemahnya organisasi serta kesatuan para perajin pandai besi sehingga terkesan berjalan sendiri-sendiri.

Kendala lain yang dihadapi pengrajin pandai besi adalah masih belum mampu memanfaatkan kemajuan informasi dan teknologi khususnya dalam hal penggunaan media teknologi untuk memasarkan produk yang mereka miliki serta teknologi dalam penggunaan peralatan produksi yang modern. Lemahnya daya saing produk yang dihasilkan oleh para perajin sehingga produk yang dihasilkan terkesan monoton (kurang kreatifitas atau diversifikasi produk), sehingga desain dan 
sentuhan teknologi yang digunakan sulit mengakses pasar lokal maupun regional. Kelemahan lainnya adalah kesulitan dalam mengakses kebutuhan bahan baku logam sehingga menyebabkan banyak perajin yang gulung tikar dan beralih untuk menggeluti profesi lain. Para pengrajin pandai besi juga mengeluhkan kurangnya modal yang mereka miliki, para perajin hanya tergantung pada modal internal bahkan kebanyakan dari perajin meminjam dana pada pengumpul (pembeli produk) sehingga harga ditentukan oleh pengumpul disebabkan tidak dapat mengakses kredit dari bank maupun lembaga keuangan lainnya dengan banyaknya persyaratan yang ditentukan.

Keberadaan peralatan pertanian tradisional seperti cangkul, linggis, parang maupun sabit pun masih tetap banyak digunakan masyarakat petani untuk mengolah lahan pertanian di Provinsi Sulawesi Selatan khususnya Kabupaten Sidrap yang terkenal sebagai penghasil padi terbesar di Provinsi Sulawesi Selatan yang hampir sebagian besar daratannya merupakan lahan pertanian, masyarakat petani, khususnya yang ada di daerah pedesaan, masih banyak yang mengandalkan dan menggunakan peralatan tradisional untuk mengolah lahan pertanian. Tidak heran usaha kerajinan pandai besi seperti sabit, cangkul maupun peralatan pertanian lain tetap laku dan dicari petani di pasar tradisional.

Teknologi proses produksi yang digunakan pengrajin pandai besi selama ini masih konvensional dan pengetahuan/keahlian secara turun temurun, demikian pula desainnya belum berorientasi pada pasar, sehinga kualitas produk yang dihasilkan tidak mampu bersaing terutama dengan produk sejenis yang dihasilkan oleh industri yang sudah menggunakan teknologi modern.

Perkembangan usaha pandai besi di Kecamatan Tellu Limpoe perlu mendapat perhatian yang besar dari pemerintah setempat maupun kalangan masyarakat luas, perhatian pemerintah terutama departemen perindustrian dan perdagangan berupa bantuan-bantuan yang dibutuhkan oleh pengrajin pandai besi memberikan dampak yang positif bagi masyarakat yang berusaha di bidang ini.
Berdasarkan fenomena yang telah dijelaskan, maka kami tertarik untuk melakukan pengabdian pada sentra pengrajin pandai besi yang berlokasi di Kecamatan Tellu Limpoe Kabupaten Sidrap agar kerajinan pandai besi ini mampu bertahan dan dapat meningkatkan kesejahteraan masyarakat pengrajin pandai besi. Diharapkan industri kerajinan pandai besi dapat menjadi ikon Kabupaten Sidrap.

\section{METODE YANG DIGUNAKAN}

Metode pendekatan yang digunakan dalam pengabdian ini berupa sosialisasi, pelatihan, pendampingan dan pembinaan pengrajin pandai besi dalam bentuk knowledge transfer (Abubakar dan Palisuri, 2018), sebagai berikut:

a. Model problem based discussion, yaitu mendiskusikan solusi permasalahan dengan pengrajin pandai besi dan pemerintah setempat mengenai kegiatan yang akan dilakukan dalam pengabdian ini.

b. Model entrepreneurship capacity building, yaitu membentuk dan meningkatkan motivasi dan perilaku kewirausahaan terhadap pengrajin pandai besi dalam berinovasi, berkreasi dan melihat peluang bisnis.

c. Model technology transfer, yaitu memberikan pengetahuan tentang manfaat dan kegunaan tehnologi dalam kegiatan usaha.

d. Merencanakan, melaksanakan, memonitor dan mengevaluasi, yaitu proses melaksanakan fungsi-fungsi manajemen untuk efesiensi dan efektivitas kegiatan usaha.

\section{PELAKSANAAN DAN HASIL KEGIATAN}

Kawasan pengrajin pandai besi di Kecamatan Tellu Limpoe Kabupaten Sidrap, tentunya selalu identik dengan aneka jenis kerajinan berbahan baku besi yang dikembangkan oleh pengrajin sekitar. Jika dulunya masyarakat kecamatan Tellu Limpoe adalah pekerja tani dan ladang musiman sebagai pencaharian utama, sekarang ini mereka mulai menengok dan menekuni usaha kerajinan pandai besi sebagai penghasilan utama dengan 
memanfaatkan bahan baku logam besi bekas dan kayu untuk dijadikan berbagai macam kerajinan yang terbuat dari logam besi.

Mitra UKM 1, merupakan salah satu mitra program yang menekuni kerajinan pandai besi sejak tahun 2007 lebih banyak melakukan produksi berdasarkan pesanan dengan beberapa jenis model kerajinan besi, berupa: pisau, parang, kapak, sabit, cangkul dan alat pertanian lainnya. Selama ini produk yang dihasilkan Mitra UKM adalah lebih banyak berbentuk alat pertanian dan alat rumah tangga dengan kisaran harga terbilang cukup terjangkau yakni antara harga Rp10.000 Rp65.000,- setiap unit. Sedangkan alat pembajak sawah umumnya berkisar Rp85.000-Rp100.000,/unit. Produksi yang dihasilkan dalam sebulan dengan menggunakan karyawan 3 sampai 4 orang sebanyak 20 unit dengan pendapatan sebesar Rp5.500.000,-

Mitra UKM 2, merupakan pengrajin pandai besi dengan besaran pendapatan berkisar $\mathrm{Rp}$. 8.500.000,-/bulan dengan menggunakan tenaga kerja sebanyak 7 orang. Akibat kelesuan pembeli akhir-akhir ini menurut kedua mitra program adalah adanya kecenderungan harga bahan baku (besi) cenderung meningkat, tenaga kerja terampil untuk pengrajin pandai besi makin berkurang dan sebagian beralih memilih bekerja sebagai pegawai toko dan buruh tani. Disisi lain, faktor pemasaran dan kemampuan inovasi juga menjadi permasalahan pengrajin pandai besi.

Uraian diatas memberikan gambaran bahwa usaha kerajinan pandai besi di Kecamatan Tellu Limpoe perlu mendapat perhatian dan penanganan yang terencana dan berkelanjutan sehingga dapat meningkatkan orientasi kewirausahaan dan program PKM di Kecamatan Tellu Limpoe Kabupaten Sidrap sangat tepat dan strategis untuk pengembangan usaha kerajinan pandai besi.

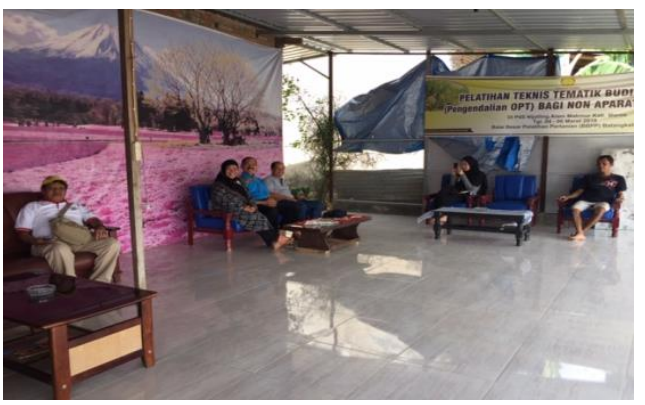

Gambar 3. Konsolidasi dengan pemerintah setempat

Solusi yang diberikan kepada usaha kerajinan pandai besi di Kecamatan Tellu Limpoe adalah melakukan sosialisasi, pelatihan, pembinaan dan pendampingan dengan beberapa kegiatan antara lain:

a. Melakukan pelatihan tentang cara pengembangan usaha melalui pedekatan tri konsep yakni konsep produksi berorientasi pasar, konsep pemasaran berorientasi pada pelayanan konsumen dan konsep keuangan yang berorientasi pada pencatatan pengeluaran dan pemasukan.

b. Pendampingan terhadap proses produksi dengan memperhatikan kuantitas, kualitas produk dan model serta efisiensi persediaan bahan baku.

c. Melakukan proses pembinaan terhadap sumber daya manusia dalam meningkatkan kemampuan dan keahlian penggunaan mesin modern.

d. Melakukan strategi pemasaran dengan pendekatan konsep marketing mix dan strategi pemasaran modern.

e. Pendampingan dan pelatihan tentang penyusunan studi kelayakan usaha dan cara penyusunan proposal pemanfaatan modal usaha perbankan.

f. Melakukan perencanaan, pengorganisasian, pelaksanaan dan evaluasi proses usaha berbasis keinginan pasar. 


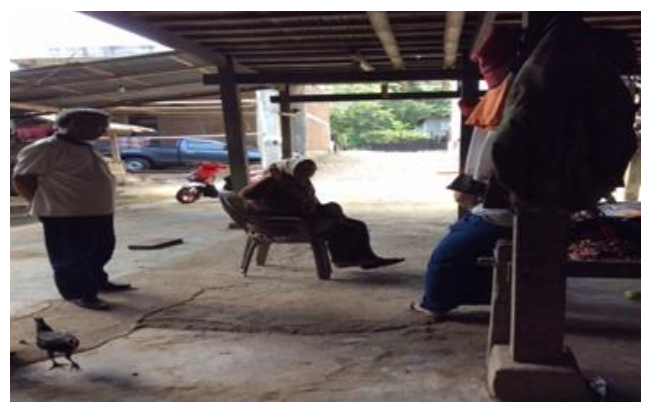

Gambar 4. Kegiatan sosialisasi

Hasil kegiatan yang dilakukan, pendapatan yang diterima dan orientasi kewirausahaan pengrajin pandai besi di Kecamatan Tellu Limpoe mengalami peningkatan dengan:

a. Melaksanakan diversifikasi produk dalam hal model dan desain dengan mengikuti keinginan pasar.

b. Bekerjasama dengan pengusaha penyedia alat pertanian dan menjalin kemitraan dengan pengusaha kebutuhan rumah tangga.

c. Meningkatkan keahlian tenaga kerja dengan memperkenalkan teknik dan sistem produksi yang lebih modern.

d. Merencanakan pengadaan bahan baku secara efisien dan melaksanakan tata kelola keuangan dengan lebih baik.

Adapun pendapatan yang diperoleh Mitra UKM

1 dan Mitra UKM 2 setelah melakukan kegiatan tersebut diatas dapat meningkat secara signifikan. Sebagai illustrasi, pada tahun 2017, untuk mitra UKM 1, produksi kerajinan pandai besi meningkat menjadi 130 unit/bulan dengan tingkat pendapatan sebesar Rp15.350.000,-/bulan dengan mempekerjakan tenaga kerja sebanyak 7-9 orang. Untuk Mitra UKM 2, dengan tenaga kerja sebanyak 10 orang dapat memproduksi 200 unit/bulan dengan pendapatan sebesar Rp24.700.000,-/bulan.

Manfaat lain yang diperoleh dari kegiatan ini adalah bertambahnya minat masyarakat Kecamatan Tellu Limpoe khususnya pemuda yang selama ini tidak produktif secara finansial untuk menekuni kerajian pandai besi ini, sehingga diharapkan dapat meningkatkan kesejahteraan keluarga. Selain itu, masyarakat yang dahulunya hanya menggantungkan penghasilan dari hasil bekerja sebagai buruh tani dan buruh ladang musiman beralih menjadi pengrajin pandai besi yang diawali dengan menjadi tenaga kerja pada pengrajin pandai besi yang telah lama menggeluti kerajinan pandai besi. Di bawah ini secara kuantitas perkembangan penjualan kerajinan pandai besi dapat dilihat Tabel 1 .

Tabel 1. Perkembangan Usaha Kerajinan Pandai Besi Kecamatan Tellu Limpoe

\begin{tabular}{lcccc}
\hline Mitra & $\begin{array}{c}\text { Sebelum } \\
\text { (Rp.000) }\end{array}$ & $\begin{array}{c}\text { Sesudah } \\
(\text { Rp.000) }\end{array}$ & \multicolumn{2}{c}{$\begin{array}{c}\text { Pengembangan } \\
\text { Usaha }\end{array}$} \\
\cline { 3 - 5 } & & & Rp.000 & $\%$ \\
\hline Mitra & $5.500,-$ & $15.350,-$ & $9.850,-$ & 179,0 \\
UKM 1 & & & & \\
\hline Mitra & $8.500,-$ & $24.700,-$ & $16.200,-$ & 190,6 \\
UKM 2 & & & & \\
\hline
\end{tabular}

Tabel 1 memberikan gambaran bahwa program PKM di pandai besi di Kecamatan Tellu Limpoe Kabupaten Sidrap yang dilaksanakan telah memberikan dampak bagi masyarakat pengrajin pandai besi, baik dampak sosial maupun dampak ekonomis. Secara ekonomi pada Tabel 1 terlihat peningkatan pendapatan setelah program pengabdian oleh Mitra UKM 1 sebesar $179.0 \%$ atau meningkat sebesar Rp9.850.000,- dari tahun sebelumnya dan Mitra UKM 2 meningkat sebesar 190,6\% atau sebesar Rp16.200.000,- dari tahun sebelumnya.

\section{KESIMPULAN}

Hasil dari pengabdian kepada masyarakat pengrajin pandai besi, dapat disimpulkan sebagai berikut:

a. Hasil produksi kerajinan pandai besi mempunyai prospek yang baik dimasa yang akan datang, hal ini ditandai dengan semakin meningkatnya permintaan akan produk kerajinan pandai besi.

b. Peningkatan keahlian sumber daya manusia dalam bidang produksi, keuangan dan pemasaran.

c. Meningkatkan pendapatan pengrajin pandai besi dengan melalui proses inovasi dan penggunaan teknologi informasi sebagai salah satu sarana memperkenalkan produk kerajinan ini kepada masyarakat luas. 


\section{UCAPAN TERIMA KASIH}

Kegiatan ini terlaksana berkat dukungan dari Universitas Bosowa, Fakultas Ekonomi dan Bisnis Universitas Bosowa, LPPM Universitas Bosowa dan aparat pemerintah Kecamatan Tellu Limpoe Kabupaten Sidrap. Kami menyampaikan apresiasi yang tinggi dan terima kasih atas segala kontribusi dan dukungannya dalam kegiatan pengabdian kepada masyarakat ini.

\section{DAFTAR PUSTAKA}

Abubakar, Herminawaty dan Palisuri, Palipada. (2018). Karakteristik Wirausaha terhadap keberlanjutan Industri Kuliner Tradisional, Prosiding Seminar Nasional dan Call for Paper, Universitas Islam Negeri Maulana Malik Ibrahim Malang.

Ardiansyah. (2017). Pengaruh Karakteristik Kewirausahaan Terhadap Keberhasilan Usaha Pada Para Pelaku Usaha Kuliner Di Seputaran Universitas Mulawarman Samarinda. eJournal Administrasi Bisnis, vol 5 (3): 626 637 ISSN 2355-5408, ejournal.adbisnis.fisip-unmul.ac.id

Tambunan TTH. (2009). UMKM di Indonesia. Bogor (ID): Ghalia Indonesia. 